\title{
PENGEMBANGAN PERANGKAT LUNAK UNTUK ANALISIS ALIRAN BEBAN TIGA FASA PADA JARINGAN TEGANGAN RENDAH DENGAN METODE NEWTON BERBASIS CALCULUS WIRTINGER
}

\author{
Hayatul Harifin ${ }^{1 *}$, Novalio Daratha ${ }^{1}$, M.Khairul Amri Rosa ${ }^{1}$ \\ ${ }^{1}$ Teknik Elektro Universitas Bengkulu, *E-mail: hayatulharifin@gmail.com
}

\begin{abstract}
Load flow analysis is a study to plan and determine the amount of power in an electric power system. During its development, industry requires a large amount of electric power and uses electrical equipment as a means of production. The benefits of an electric load flow analysis are to find out the amount of power in the electric power system whether it still meets predetermined limits, and to find out the amount of voltage at each point, and to obtain initial conditions for the new system planning. Load flow analysis begins calculating the active power and reactive power at each node (bus) installed, loading on the channel or conductor, the load flow calculation will be assisted using the Julia program. From the results of calculations using the Julia program, the voltage at each point with the smallest stress is obtained, namely the 10th point of $209.89-\mathbf{j 1 0 . 3 4 V}$ for phase $A,-107.39$ - j186.87V for phase $B,-\mathbf{1 0 8 . 1 2}+\mathbf{j 1 7 8 , 5 1 V}$ for phase $C$ Key Words: Drop Voltage, Julia, Load Flow
\end{abstract}

\section{Pendahuluan}

Ada tiga studi yang sangat penting dalam sistem tenaga yaitu, studi aliran daya, studi hubung singkat, dan studi stabilitas. Ketiga studi tersebut saling berkaitan dan perlu untuk di lakukan pengujian secara berkala untuk mengetahui kualitas listrik yang di salurkan dalam keadaan baik.

Studi aliran beban adalah penentuan atau perhitungan tegangan, arus dan faktor daya atau daya reaktif yang terdapat pada berbagai titik dalam suatu jaringan listrik pada keadaan normal, baik yang sedang berjalan maupun yang diharapkan akan terjadi dimasa yang akan datang. Studi aliran beban sangat penting dalam perencanaan pengembangan suatu sistem listrik untuk masa yang akan datang, karena pengoperasian yang baik banyak tergantung pada diketahuinya efek interkoneksi dengan sistem tenaga yang lain dan beban yang baru terpasang.

Dalam perhitungan studi aliran beban tergantung jenis jaringannya, semakin rumit koneksi antar jaringan maka semakin rumit juga perhitungan iterasi aliran bebannya. Titik-titik persambungan pada jaringan akan mempengaruhi perhitungan pada titik sambungan lainnya sehingga pada jaringan yang memiliki banyak titik persambungan akan mengalami perhitungan yang sangat rumit.

Beberapa metode yang biasa digunakan untuk menyelesaikan studi aliran beban dengan metode iterasi (numerik) telah banyak di kembangkan seiring dengan perkembangan konfigurasi jaringan listrik, beberapa diantaranya yang paling populer adalah metode Gauss seidel, metode Newton Raphson dan metode decoupled. Metode ini dapat dilakukan dengan perhitungan manual ataupun dengan bantuan komputer.

Salah satu metode aliran beban yang banyak digunakan dalam jaringan distribusi adalah Backward Forward Sweep (BFS)[1], yang dikembangkan dengan mengambil keuntungan dari topologi radial, sehingga menghasilkan perhitungan yang efisien. Namun, kurangnya matriks Jacobian membuatnya tidak praktis untuk digunakan dalam Teknik CPF. Selain itu, metode BFS tidak dapat menemukan titik sisi kiri kurva QV atau sisi rendah kurva PV, karena masalah konvergensi pada solusi tegangan rendah [2].

Pada penelitian ini akan dibahas tegangan setiap titik dan arus setiap saluran yang terjadi pada saluran jaringan tegangan rendah (JTR). Dalam hal ini untuk mengetahuinya digunakan lah yang bersumber dari IEEE feeder 13, yang akan di simulasikan menggunakan program Julia, sehingga peneliti mengambil judul Pengembangan Perangkat Lunak Untuk Analisis Aliran Beban Tiga Fasa Pada Jaringan Tegangan Rendah Dengan Metode Newton Berbasis Calculus Wirtinger.

\section{LANDASAN TEORI}

\section{A. Matriks Insidensi}

Formulasi yang diusulkan dalam penelitian ini, disebut Radial Complex-Rated (RFC) yaitu membandingkan penurunan tegangan cabang yang dihitung dengan dua mode, yang pertama dihitung dari arus titik yang diinjeksi kan dan yang lainnya dari 




Gambar 1 Titik Percabangan Arus Pada Aliran Daya[7]

tegangan titik tersebut, masalah aliran beban dianggap terpecahkan ketika kedua tegangan turun sesuai.

Perhitungan penurunan tegangan menggunakan matriks berdasarkan matriks L yang dijelaskan di bawah ini, matriks menunjukan hubungan antara titik dan arus aliran beban yang diinjeksi kan dari system yang terdapat pada Gambar 1 titik nol menunjukan adalah simpul referensi dan ada trafo.

Dari Gambar 1 diantara titik 3 dan 4 didapat persamaan yang di muat dalam matriks berikut:

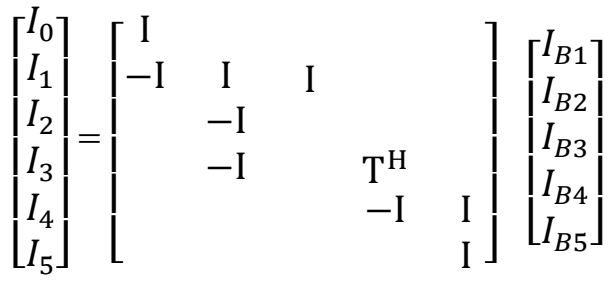

Nilai $I_{\mathrm{i}}$ adalah arus titik 3 fasa dari simpul I, dan $I_{B j}$ adalah arus aliran cabang dari J. Setiap kolom L dikaitkan dengan cabang dan setiap baris dengan simpul. Ikuti langkah-langkah berikut untuk membentuk matriks pada setiap cabang:

Atur I disimpul akhir.

Atur $\mathrm{T}^{\mathrm{H}}$ disisi pengirim titik.

Dimana matriks variabel berukuran $3 \times 3$, dan $\mathrm{T}$ adalah matriks rasio transformator. $(\mathrm{T})^{\mathrm{H}}$ menunjukan matriks transpose konjugasi. Untuk garis tanpa transformator $\mathrm{T}=\mathrm{I}$, dan lampiran $\mathrm{D}$ menunjukan $\mathrm{T}$ untuk beberapa koneksi antara hubungan transformator. Dengan demikian, begitu terbentuk L untuk sistem apapun dengan langkah-langkah yang di sebutkan diatas, Persamaan 2.2 mendefinisikan hubungan antara titik I yang dikirimkan antara aliran cabang. Hubungan tersebut sesuai dengan hukum Kirchhoff arus dan dapat dilihat pada Persamaan 2.2.

$$
I=\mathrm{L} I_{B}
$$

Dan juga, jumlah kerugian daya dalam cabang sistem sama dengan jumlah arus yang dikirimkan pada titik, hubungan ini ditunjukkan pada Persamaan 2.3 $\Delta \mathrm{V}_{\mathrm{B}}$ dan $\mathrm{V}$ penurunan tegangan cabang pada masing-masing titik percabangan. Dalam mensubstitusikan Persamaan 2.1 dan 2.2 maka dapat di temukan persamaan baru hasil substitusi pada Persamaan 2.3 dan 2.4 sesuai dengan hukum Kirchhoff arus.

$$
\begin{gathered}
\mathrm{I}_{B}{ }^{\mathrm{H}} \Delta \mathrm{V}_{\mathrm{B}}=I^{\mathrm{H}} \mathrm{V} \\
\Delta \mathrm{V}_{\mathrm{B}}=\mathrm{L}^{\mathrm{H}} \mathrm{V}
\end{gathered}
$$

Penting diingat bahwa L menyediakan hubungan antara arus dan konjugasi transpose nya dan menyediakan hubungan antara tegangan.

\section{B. Metode Newton Raphson}

Metode newton Raphson menggunakan satu titik awal (initial value) sebagai tebakan awal, memerlukan slope atau gradian pada titik tersebut, dan barisan titik potong garis singgung nya dengan sumbu-X. Karena itu metode gagal digunakan jika pemilihan titik awal memberikan nilai turunannya nol. Metode ini menggunakan konsep konvergen barisan dan iterasi kekonvergensiannya dipandang cepat dan berefek galat kecil. Konsep dasar teoritis metode Newton-Raphson secara geometri diperoleh dari kekonvergenan barisan titik-titik potong antara garis singgung kurva dan sumbu$\mathrm{X}$, dan secara analisis melakukan pemotongan (truncation) fungsi pada deret Taylor.

Permasalahan aliran beban akan terselesaikan ketika $\mathrm{f}$ dan $\mathrm{f}_{\mathrm{GV}}$ sama dengan nol:

$$
\left[F\left(V_{N}\right)\right]=0
$$

Dimana $\mathrm{f}_{\mathrm{GV}} \quad\left[\mathrm{f}_{\mathrm{PV}} \mathrm{f}_{\mathrm{VV}}\right]$ dan $\mathrm{S}_{\mathrm{GV}} \quad\left[\mathrm{S}_{\mathrm{PV}} \mathrm{S}_{\mathrm{VV}}\right]$ karena masalah ini tidak linier, maka diperlukan metode yang berulang. Metode Newton Raphson bisa diaplikasikan untuk masalah nilai kompleks menggunakan Calculus Wirtinger[6].

\section{Metodologi}

Pada bab ini metode yang digunakan dalam penyelesaian algoritmya aliran beban merujuk pada jurnal [7] dengan mempertimbangkan tidak memasukan pengaruh OLTC dan pengaruh dari sisi genertor.

\section{A. Diagram Blok Perancangan}

Penelitian ini dimulai dengan tahapan studi literatur untuk mendapatkan rumusan atau formulaformula yang nantinya akan digunakan dalam perhitungan dan analisa data. Pada tahapan ini formula yang diperoleh 




Gambar 2. Diagram Pengoperasian Program

yaitu rumusan mendapatkan tegangan di setiap titik dan arus pada masing-masing saluran berdasarkan metoda Newton Raphson berbasis calculus Wirtinger. Tahapan selanjutnya yaitu pengumpulan data dari lokasi penelitian kemudian dilanjutkan dengan pembuatan program dan pengolahan data, yaitu menghitung data-data yang diperoleh selama penelitian dan menganalisa sesuai metodologi penelitian, flowchart program dapat dilihat pada Gambar 2 Tahapan yang terakhir adalah menyimpulkan hasil tahapan-tahapan sebelumnya. Hasil akhir dari penelitian ini adalah mendapatkan besar tegangan pada setiap tiitk dan arus pada setiap saluran.

\section{B. Penjabaran Penyelesaian Studi Aliran Beban}

Urutan langkah-langkah penyelesaian Studi Aliran Beban seperti berikut:

- Blok 1 Beban Vektor Zip

Vektor $S_{l y}$ dan $S_{l \Delta}$ bergantung pada VN dan $V_{\Delta}$, seperti yang ditunjukan pada persamaan berikut vektor $S_{l 0 y}$ dan $S_{l 0 \Delta}$ adalah beban bintang dan beban delta yang memuat pada semua titik pada tegangan nominal.

$$
\begin{gathered}
S_{l y}=S_{L Z Y} \odot V_{N} \odot V *_{N}+S_{L I Y} \odot\left[V_{N} \odot V *_{N}\right]^{1 / 2}+S_{L P Y} \\
S_{l \Delta}=S_{L Z Y} \odot V_{\Delta} \odot V *_{\Delta}+S_{L I Y} \odot\left[V_{\Delta} \odot V *_{\Delta}\right]^{1 / 2}+S_{L P \Delta}
\end{gathered}
$$

\section{- $\quad$ Encoding}

Dalam tahapan encoding dilakukan dengan mengartikan permasalahan ke dalam bahasa pemrograman sehingga Julia dapat melakukan perhitungan. Dalam permasalahan studi aliran beban. Data awal dalam menyelesaikan studi aliran beban diinputkan kedalam program, lalu akan disusun kedalam sebuah matriks. Setelah itu akan diinstall package yang di perlukan dalam menjalankan program, package yang di pakai adalah LinierAlgebra.setelah itu akan dilakukan operasi matematika seperti berikut.

\section{- Perkalian dan Pembagian Elemen Wise}

Perkalian elemen wise $\odot$ yaitu mengkalikan masingmasing elemen dalam dua buah matriks yang akan menghasilkan matriks yang sama dengan matriks sebelumnya. Pembagian elemen wise $1 /(\cdot)$ yaitu mebagikan masing-masing elemen dalam dua buah matriks yang akan menghasilkan matriks yang sama dengan matriks sebelumnya.

- Matriks Konjugasi dan Matriks Transpose

matriks konjugasi $(\cdot)^{*}$ yaitu operasi yang melakukan perubahan tanda pada bilangan kompleks di bagian imajiner. Matriks transpose $(\cdot)^{\mathrm{T}}$ yaitu operasi matriks yang memungkinkan perubahan posisi di dalam suatu matriks, dengan menghasilkan matriks dengan baris jadi kolom serta kolom menjadi baris.

- Matriks konjugasi Transpose

Matriks konjugasi transpose $(\cdot)^{\mathrm{H}}$ adalah sebuah operasi matematika yang dimana operasi ini akan melakukan konjugasi dan transpose secara bersamaan, didalam beberapa hal operasi ini sangat memungkinkan untuk mempermudah dalam melakukan operasi matematika pada sistem matriks yang rumit.

- Blok 2 Formulasi Masalah Aliran Beban

Tujuannya adalah mendefinisikan sebuah vektor fungsi $\mathrm{F}$ dan masalah aliran beban akan terselesaikan ketika Vn mendahului F untuk menjadi nol.

$$
F=V_{R}+L_{C}{ }^{\mathrm{H}} V_{N}-\left[Z_{B}\right] L_{C}^{-1} I_{N}
$$

\section{- Blok 3 Kriteria Penyelesaian Iterasi}

Untuk menerapkan metode Newton Raphson untuk fungsi vektor baru dapat didefinisikan $\left.F_{\left(V_{N} S_{G V} V{ }_{N} S * G V\right.}\right)$ dan permasalah aliran beban dapat diselesaikan dengan Persamaan Berikut

$$
F_{\left(V_{N} S_{G V} V{ }_{N} S * G V\right)}=\left[\begin{array}{c}
\left.f_{\left(V_{N} S_{G V} V{ }_{N} S * G V\right.}\right) \\
f_{G V}\left(V_{N} S_{G V} V{ }_{N} S * G V\right) \\
\left.f_{\left(V_{N} S_{G V} V{ }^{*} N\right.}^{*} S *_{G V}\right) \\
\left.f^{*}{ }_{G V\left(V_{N} S_{G V} V{ }_{N} S * G V\right.}\right)
\end{array}\right]=0
$$

Meskipun ukuran fungsi vektor dan vektor variabel digandakan (ingat bahwa $V^{*}{ }_{N}$ dan $S^{*}{ }_{G V}$ dianggap 
sebagai variabel independen $V_{N}$ dan $S_{G V}$ dalam Calculus Wirtinger, dengan cara ini $F_{\left(V_{N} S_{G V}{ }^{*}{ }_{N} S{ }_{G V}\right)}$ dianggap sebagai fungsi analitis. Fakta ini memungkinkan perhitungan matriks Jacobian tanpa perlu memecah formulasi menjadi dua formulasi yang bernilai nyata.

- Blok 4 Jacobian dan Matriks Invers Jacobian

Matriks Jacobian dari $F_{\left(V_{N} S_{G V} V{ }^{*} S{ }^{*} G V\right)}$ dibentuk dari :

$$
\begin{aligned}
& \mathbf{J}=\left[\begin{array}{ll}
j_{A} & j_{B} \\
j^{*}{ }_{B} & j^{*}{ }_{A}
\end{array}\right]
\end{aligned}
$$

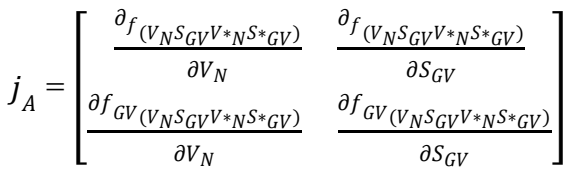

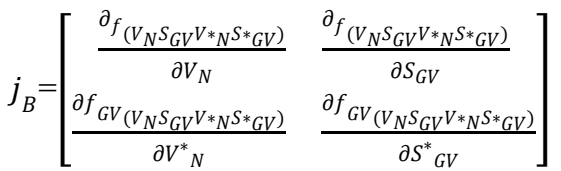

Dan matriks invers Jacobian $J^{-1}$ menjadi :

$$
\begin{aligned}
& J^{-1}=\left[\begin{array}{cc}
\Gamma_{A} & \Gamma_{B} \\
\Gamma_{B}^{*} & \Gamma_{A}^{*}
\end{array}\right] \\
& \Gamma_{A}=\left|j_{A}-M j^{*}{ }_{B}\right|^{-1}
\end{aligned}
$$

- Blok 5 Pembaruan Variabel

Dalam mengurangi jumlah perhitungan hanya $\Delta_{\mathrm{z}}=\left|\Delta V_{N} \Delta S_{G V}\right|^{\mathrm{T}}$ yang akan dihitung, karena $\left|\Delta V *_{N} \Delta S *_{G V}\right|$ adalah konjugasi dari $\Delta_{\mathrm{z}}$ maka diperoleh Persamaan berikut

$$
\begin{gathered}
\Delta_{\mathrm{z}}=\Gamma_{A}\left(M h^{*}-h\right) \\
H=\left[\begin{array}{c}
f \\
f_{G V}
\end{array}\right]
\end{gathered}
$$

\section{Hasil dan Pembahasan}

Pada bab ini akan dijelaskan tahapan encoding dari masing-masing blok di Gambar 2 pada bab sebelumnya, dan melihat hasil dari perhitungan studi aliran beban.

\section{A. Blok 1}

Blok 1 menjabarkan tentang penginputan berbagai data yang diperlukan dalam melakukan studi aliran beban, hasil dari inputan nilai dapat dilihat pada subbab F, Blok ini mengimplementasikan Persamaan 3 kedalam bentuk Julia, coding dapat dilihat seperti berikut

1. Matriks Identitas

2. $I=\left[\begin{array}{lllllllll}1 & 0 & 0 ; & 0 & 1 & 0 ; & 0 & 0 & 1\end{array}\right] ;$

3. $\mathrm{Zm}=\left[\begin{array}{lllllllll}0 & 0 & 0 ; & 0 & 0 & 0 ; & 0 & 0 & 0\end{array}\right]$;

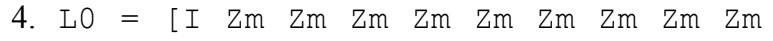
$\mathrm{Zm}$ ]

5. \# Mtatriks Isidensi

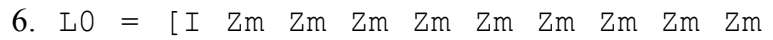
$\mathrm{Zm}$ ]

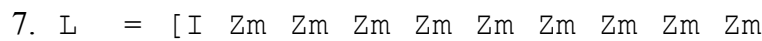
$\mathrm{Zm} ;-\mathrm{I}$ I I Zm Zm Zm Zm Zm Zm Zm Zm; $\mathrm{Zm} \mathrm{-I} \mathrm{I} \mathrm{Zm} \mathrm{Zm} \mathrm{Zm} \mathrm{Zm} \mathrm{Zm} \mathrm{Zm} \mathrm{Zm} \mathrm{Zm;} \mathrm{Zm}$ Zm -I Zm Zm Zm Zm Zm Zm Zm Zm; Zm Zm $\mathrm{Zm} \mathrm{-I} \mathrm{Zm} \mathrm{Zm} \mathrm{Zm} \mathrm{Zm} \mathrm{Zm} \mathrm{Zm} \mathrm{Zm;} \mathrm{Zm} \mathrm{Zm} \mathrm{Zm}$ $\mathrm{Zm} \mathrm{-I} \mathrm{I} \mathrm{I} \mathrm{I} \mathrm{Zm} \mathrm{Zm} \mathrm{Zm;} \mathrm{Zm} \mathrm{Zm} \mathrm{Zm} \mathrm{Zm} \mathrm{Zm}$ -I I I Zm Zm Zm; Zm Zm Zm Zm Zm Zm I Zm Zm Zm Zm; Zm Zm Zm Zm Zm Zm Zm -I Zm Zm Zm; Zm Zm Zm Zm Zm Zm Zm Zm -I Zm Zm; Zm Zm Zm Zm Zm Zm Zm Zm Zm $-I \mathrm{I}$; Zm Zm Zm Zm Zm Zm Zm Zm Zm Zm $-\mathrm{I}]$;

8. $\mathrm{LC}=[-I$ I I Zm Zm Zm Zm Zm Zm Zm Zm; Zm -I I Zm Zm Zm Zm Zm Zm Zm Zm; Zm Zm -I Zm Zm Zm Zm Zm Zm Zm Zm; Zm Zm $\mathrm{Zm} \mathrm{-I} \mathrm{Zm} \mathrm{Zm} \mathrm{Zm} \mathrm{Zm} \mathrm{Zm} \mathrm{Zm} \mathrm{Zm;} \mathrm{Zm} \mathrm{Zm} \mathrm{Zm}$ $\mathrm{Zm} \mathrm{-I} \mathrm{I} \mathrm{I} \mathrm{I} \mathrm{Zm} \mathrm{Zm} \mathrm{Zm;} \mathrm{Zm} \mathrm{Zm} \mathrm{Zm} \mathrm{Zm} \mathrm{Zm}$ -I I I Zm Zm Zm; Zm Zm Zm Zm Zm Zm I Zm Zm Zm Zm; Zm Zm Zm Zm Zm Zm Zm -I Zm Zm Zm; Zm Zm Zm Zm Zm Zm Zm Zm -I Zm Zm; Zm Zm Zm Zm Zm Zm Zm Zm Zm $-I \mathrm{I} ; \mathrm{Zm} \mathrm{Zm} \mathrm{Zm} \mathrm{Zm} \mathrm{Zm} \mathrm{Zm} \mathrm{Zm} \mathrm{Zm} \mathrm{Zm} \mathrm{Zm}$ $-\mathrm{I}]$;

9. Block diagonal matrix of the branch' simpedances


$\mathrm{Zm} \mathrm{Zm;} \mathrm{Zm} \mathrm{Im12} \mathrm{Zm} \mathrm{Zm} \mathrm{Zm} \mathrm{Zm} \mathrm{Zm} \mathrm{Zm} \mathrm{Zm}$ $\mathrm{Zm} \mathrm{Zm;} \mathrm{Zm} \mathrm{Zm} \mathrm{Im23} \mathrm{Zm} \mathrm{Zm} \mathrm{Zm} \mathrm{Zm} \mathrm{Zm} \mathrm{Zm}$ $\mathrm{Zm} \mathrm{Zm;} \mathrm{Zm} \mathrm{Zm} \mathrm{Zm} \mathrm{Im14} \mathrm{Zm} \mathrm{Zm} \mathrm{Zm} \mathrm{Zm} \mathrm{Zm}$ $\mathrm{Zm} \mathrm{Zm;} \mathrm{Zm} \mathrm{Zm} \mathrm{Zm} \mathrm{Zm} \mathrm{Im16} \mathrm{Zm} \mathrm{Zm} \mathrm{Zm} \mathrm{Zm}$ $\mathrm{Zm} \mathrm{Zm;} \mathrm{Zm} \mathrm{Zm} \mathrm{Zm} \mathrm{Zm} \mathrm{Zm} \mathrm{Im67} \mathrm{Zm} \mathrm{Zm} \mathrm{Zm}$ $\mathrm{Zm} \mathrm{Zm;} \mathrm{Zm} \mathrm{Zm} \mathrm{Zm} \mathrm{Zm} \mathrm{Zm} \mathrm{Zm} \operatorname{Im} 78 \mathrm{Zm} \mathrm{Zm}$ $\mathrm{Zm} \mathrm{Zm;} \mathrm{Zm} \mathrm{Zm} \mathrm{Zm} \mathrm{Zm} \mathrm{Zm} \mathrm{Zm} \mathrm{Zm} \mathrm{Im79} \mathrm{Zm}$ $\mathrm{Zm} \mathrm{Zm;} \mathrm{Zm} \mathrm{Zm} \mathrm{Zm} \mathrm{Zm} \mathrm{Zm} \mathrm{Zm} \mathrm{Zm} \mathrm{Zm} \mathrm{Im610}$ $\mathrm{Zm} \mathrm{Zm;} \mathrm{Zm} \mathrm{Zm} \mathrm{Zm} \mathrm{Zm} \mathrm{Zm} \mathrm{Zm} \mathrm{Zm} \mathrm{Zm} \mathrm{Zm}$ Im611 Zm; Zm Zm Zm Zm Zm Zm Zm Zm Zm Zm Im1112];

11. $\mathrm{yd}=\left[\begin{array}{lllllllll}1 & -1 & 0 ; & 0 & 1 & -1 ; & -1 & 0 & 1\end{array}\right] ;$


$\mathrm{Zm}$; $\mathrm{Zm} \mathrm{yd} \mathrm{Zm} \mathrm{Zm} \mathrm{Zm} \mathrm{Zm} \mathrm{Zm} \mathrm{Zm} \mathrm{Zm} \mathrm{Zm} \mathrm{Zm;}$ $\mathrm{Zm} \mathrm{Zm} \mathrm{yd} \mathrm{Zm} \mathrm{Zm} \mathrm{Zm} \mathrm{Zm} \mathrm{Zm} \mathrm{Zm} \mathrm{Zm} \mathrm{Zm;} \mathrm{Zm}$ $\mathrm{Zm} \mathrm{Zm} \mathrm{yd} \mathrm{Zm} \mathrm{Zm} \mathrm{Zm} \mathrm{Zm} \mathrm{Zm} \mathrm{Zm} \mathrm{Zm;} \mathrm{Zm} \mathrm{Zm}$ $\mathrm{Zm} \mathrm{Zm} \mathrm{yd} \mathrm{Zm} \mathrm{Zm} \mathrm{Zm} \mathrm{Zm} \mathrm{Zm} \mathrm{Zm;} \mathrm{Zm} \mathrm{Zm} \mathrm{Zm}$

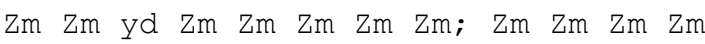
$\mathrm{Zm} \mathrm{Zm} \mathrm{yd} \mathrm{Zm} \mathrm{Zm} \mathrm{Zm} \mathrm{Zm;} \mathrm{Zm} \mathrm{Zm} \mathrm{Zm} \mathrm{Zm} \mathrm{Zm}$ $\mathrm{Zm} \mathrm{Zm} \mathrm{yd} \mathrm{Zm} \mathrm{Zm} \mathrm{Zm;} \mathrm{Zm} \mathrm{Zm} \mathrm{Zm} \mathrm{Zm} \mathrm{Zm} \mathrm{Zm}$

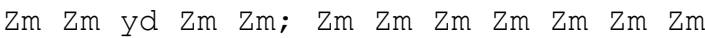
$\mathrm{Zm} \mathrm{Zm} \mathrm{yd} \mathrm{Zm;} \mathrm{Zm} \mathrm{Zm} \mathrm{Zm} \mathrm{Zm} \mathrm{Zm} \mathrm{Zm} \mathrm{Zm} \mathrm{Zm}$ Zm Zm yd]; 


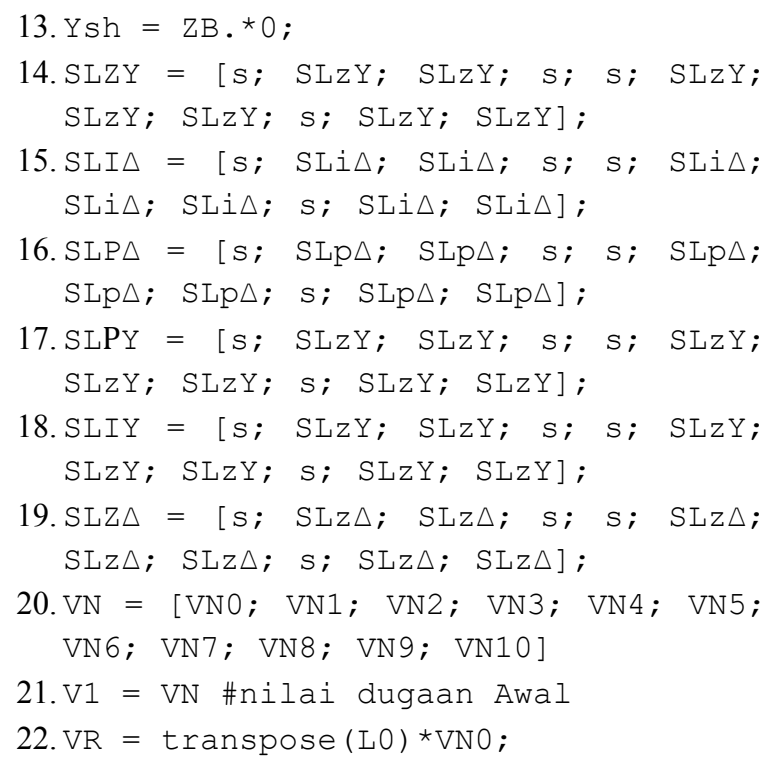

\section{B. Blok 2}

Blok 2 menjabarkan perhitungan nilai f dimana nilai $\mathrm{f}$ adalah selisih nilai tegangan yg di hitung dari titik nodal pengiriman dan dari titik nodal penerima, Blok ini mengimplementasikan Persamaan 4 kedalam bentuk Julia, bentuk coding dapat dlihat seperti berikut



\section{Blok 3}

Blok 3 menjabarkan perhitungan nilai h dimana jika nilai $h$ bernilai kecil dari nilai referensi yaitu nilai efsilon makan iterasi berhenti dan nilai tegangan sebenarnya di tampilkan dan hasil dari perhitungan dapat dilihat pada subbab H, Blok ini mengimplementasikan Persamaan 5 kedalam bentuk Julia, bentuk coding dapat dilihat seperti berikut

1. $\mathrm{h}=\mathrm{f}$

2. $\mathrm{H}=\operatorname{maximum}(\mathrm{abs}$. (f));

3. if $\mathrm{H}>$ epsilon

\section{Blok 4}

Blok 4 menjabarkan perhitungan matriks jacobian, dimana perhitungan ini di perlukan jika nilai dari h masih lebih besar dari nilai efsilon yang ditetapkan, Blok ini mengimplementasikan Persamaan 6 kedalam bentuk Julia, bentuk coding dapat dilihat sebagai berikut

1. $\mathrm{D}=$ Diagonal (- Conj (SLZ $\triangle)$ -

$(\operatorname{conj}(\operatorname{SLI} \Delta) / 2)) \cdot *(1 / \mathrm{abs} \cdot(\mathrm{V} \Delta))$;

2. $\mathrm{C}=$ Diagonal (- $\operatorname{conj}(\mathrm{SLZY})-$

$(\operatorname{conj}(\operatorname{SLIY}) / 2)) \cdot{ }^{\star}(1 / \mathrm{abs} \cdot(\mathrm{VN}))$;

3. $\mathrm{B}=\mathrm{C}+$ transpose $(\mathrm{YD}) \star \mathrm{D} * \mathrm{YD}+\mathrm{Ysh}$

4. $X=$ transpose $(\mathrm{LC})$;

5. JA $=\operatorname{conj}(\mathrm{X})-(\mathrm{ZB} * \operatorname{inv}(\mathrm{LC}) * \mathrm{~B})$;

6. D1=Diagonal $\left(\operatorname{conj}(\mathrm{SLI} \triangle / 2) \cdot{ }^{\star} \mathrm{VN} . \wedge 0.5 . *\right.$

$\left(1 / \operatorname{conj}(V \triangle) \cdot{ }^{\wedge} 1.5\right)+(\operatorname{conj}(\operatorname{SLP} \triangle)) . *(1 / \mathrm{C}$ onj (VN) $\left.\left.\cdot{ }^{\wedge} 2\right)\right)$;

7. $\mathrm{Cl}=$ Diagonal $\left(\operatorname{conj}(\mathrm{SLIY} / 2) \cdot{ }^{\star} \mathrm{VN} \cdot{ }^{\wedge} 0.5 . *\right.$

$\left(1 / \operatorname{conj}(\mathrm{VN}) \cdot{ }^{\wedge} 1 \cdot 5\right)+(\operatorname{conj}(\mathrm{SLPY})) \cdot{ }^{\star}(1 / \mathrm{C}$ onj (VN) $\left.\left.\cdot{ }^{\wedge} 2\right)\right)$;

\section{E. Blok 5}

Blok 5 menjabarkan tentang pembaruan nilai Vn untuk melakukan perhitungan nilai h yang baru, nilai Vn ini di dapatkan dari hasil output perhitungan matriks jacobian pada blok sebelumnya dan dilakukan substitusikan pada rumus yang baru, Blok ini mengimplementasikan Persamaan 7 kedalam bentuk Julia hasil coding dapat dilihat seperti berikut

1. $\mathrm{B} 1=\mathrm{C} 1+$ transpose $(\mathrm{YD}) \star \mathrm{D} 1 * \mathrm{YD}$;

2. $\mathrm{JB}=-\mathrm{ZB} * \operatorname{inv}(\mathrm{LC}) * \mathrm{~B} 1$;

3. $\mathrm{M}=\mathrm{JB} * \operatorname{inv}(\operatorname{conj}(\mathrm{A}))$;

4. $\Gamma A=\operatorname{inv}\left(J A-\left(M^{*} \operatorname{conj}(J B)\right)\right)$;

5. $V \Delta z=\Gamma A *(M * \operatorname{conj}(h)-h)$

6. $\mathrm{VN}=\mathrm{VN}+\mathrm{V} \Delta \mathrm{z}$

7. print (H) ;

8. print (" ") ;

9. end

Blok 2 hingga 5 akan melakukan looping secara terus menerus hingga nilai $h$ lebih kecil dari nilai referensi efsilon, setelah itu looping akan berhenti dan menampilkan nilai tegangan yang sebenarnya pada masing-masing titik, setelah di dapatkan tegangan dapat dihitung nilai arus pada masing-masing saluran dan hasil perhitungan dapat dilihat pada subbab I, dengan coding seperti berikut
1. $\mathrm{IB}=\operatorname{inv}(\mathrm{Lc}) * \mathrm{IN}$
2. sudut $=$ angle.(IB)*180/3.14

\section{F. Perhitungan Impedansi Saluran}

Pengumpulan data impedansi saluran JTR dilakukan di setiap saluran jaringan tegangan rendah (JTR) darri 
Tabel 1 Impedansi Saluran

\begin{tabular}{|c|c|c|c|}
\hline \multirow[b]{2}{*}{$\begin{array}{l}\text { Titik } \\
\text { A-B }\end{array}$} & \multicolumn{3}{|c|}{ Impedansi Saluran (Ohm) } \\
\hline & $\begin{array}{r}\text { Phasa A } \\
\text { (Ohm) }\end{array}$ & $\begin{array}{l}\text { Phasa B } \\
\text { (Ohm) }\end{array}$ & $\begin{array}{c}\text { Phasa C } \\
\text { (Ohm) }\end{array}$ \\
\hline $\begin{array}{l}632- \\
645\end{array}$ & $\begin{array}{c}0,0+j 0,0 \\
0,12+j 0,12 \\
0,12+j 0,12\end{array}$ & $\begin{array}{c}0,0+\mathrm{j} 0,0 \\
0,12+\mathrm{j} 0,12 \\
0,01+\mathrm{j} 0,04\end{array}$ & $\begin{array}{c}0,0+\mathrm{j} 0,0 \\
0,01+\mathrm{j} 0,04 \\
0,12+\mathrm{j} 0,12\end{array}$ \\
\hline $\begin{array}{l}632- \\
633\end{array}$ & $\begin{array}{l}0,07+j 0,11 \\
0,01+j 0,04 \\
0,01+j 0,04\end{array}$ & $\begin{array}{c}0,01+\mathrm{j} 0,04 \\
0,07+\mathrm{j} 0,10 \\
0,01+\mathrm{j} 0,03\end{array}$ & $\begin{array}{c}0,01+\mathrm{j} 0,04 \\
0,01+\mathrm{j} 0,03 \\
0,07[+\mathrm{j} 0,11\end{array}$ \\
\hline $\begin{array}{l}645- \\
646\end{array}$ & $\begin{array}{c}0,0+\mathrm{j} 0,0 \\
0,07+\mathrm{j} 0,07 \\
0,07+\mathrm{j} 0,07\end{array}$ & $\begin{array}{c}0,0+\mathrm{j} 0,0 \\
0,07+\mathrm{j} 0,07 \\
0,01+\mathrm{j} 0,02\end{array}$ & $\begin{array}{c}0,0+\mathrm{j} 0,0 \\
0,01+\mathrm{j} 0,02 \\
0,07+\mathrm{j} 0,07\end{array}$ \\
\hline $\begin{array}{l}650- \\
632\end{array}$ & $\begin{array}{c}0,13+\mathrm{j} 0,38 \\
0,05+\mathrm{j} 0,16 \\
0,05+\mathrm{j} 0,16\end{array}$ & $\begin{array}{l}0,05+\mathrm{j} 0,19 \\
0,12+\mathrm{j} 0,39 \\
0,05+\mathrm{j} 0,14\end{array}$ & $\begin{array}{c}0,05+\mathrm{j} 0,16 \\
0,05+\mathrm{j} 0,14 \\
0,12+\mathrm{j} 0,39\end{array}$ \\
\hline $\begin{array}{l}684- \\
652\end{array}$ & $\begin{array}{c}0,20+\mathrm{j} 0,07 \\
0,0+\mathrm{j} 0.0 \\
0,0+\mathrm{j} 0.0\end{array}$ & $\begin{array}{l}0,0+j 0,0 \\
0,0+j 0,0 \\
0,0+j 0,0\end{array}$ & $\begin{array}{l}0,0+\mathrm{j} 0,0 \\
0,0+\mathrm{j} 0,0 \\
0,0+\mathrm{j} 0,0\end{array}$ \\
\hline $\begin{array}{l}632- \\
671\end{array}$ & $\begin{array}{c}0,13+j 0,38 \\
0,05+j 0,16 \\
0,05+j 0,16\end{array}$ & $\begin{array}{c}0,05+\mathrm{j} 0,19 \\
0,12+\mathrm{j} 0,39 \\
0,05+\mathrm{j} 0,14\end{array}$ & $\begin{array}{c}0,05+\mathrm{j} 0,16 \\
0,05+\mathrm{j} 0,14 \\
0,12+\mathrm{j} 0,39\end{array}$ \\
\hline $\begin{array}{l}671- \\
684\end{array}$ & $\begin{array}{l}0,07+\mathrm{j} 0,07 \\
0,01+\mathrm{j} 0,02 \\
0,01+\mathrm{j} 0,02\end{array}$ & $\begin{array}{l}0,0+\mathrm{j} 0,0 \\
0,0+\mathrm{j} 0,0 \\
0,0+\mathrm{j} 0,0\end{array}$ & $\begin{array}{c}0,01+\mathrm{j} 0,02 \\
0,0+\mathrm{j} 0,0 \\
0,07+\mathrm{j} 0,07\end{array}$ \\
\hline $\begin{array}{l}671- \\
680\end{array}$ & $\begin{array}{c}0,06+j 0,19 \\
0,02+j 0,08 \\
0,02+j 0,08\end{array}$ & $\begin{array}{c}0,02+j 0,09 \\
0,06+j 0,19 \\
0,02+j 0,07\end{array}$ & $\begin{array}{l}0,02+\mathrm{j} 0,08 \\
0,02+\mathrm{j} 0,07 \\
0,06+\mathrm{j} 0,19\end{array}$ \\
\hline $\begin{array}{l}671- \\
692\end{array}$ & $\begin{array}{l}0,0+j 0,0 \\
0,0+j 0,0 \\
0,0+j 0,0\end{array}$ & $\begin{array}{l}0,0+j 0,0 \\
0,0+j 0,0 \\
0,0+j 0,0\end{array}$ & $\begin{array}{l}0,0+\mathrm{j} 0,0 \\
0,0+\mathrm{j} 0,0 \\
0,0+\mathrm{j} 0,0\end{array}$ \\
\hline $\begin{array}{l}\text { 684- } \\
611\end{array}$ & $\begin{array}{l}0,0+j 0,0 \\
0,0+j 0,0 \\
0,0+j 0,0\end{array}$ & $\begin{array}{l}0,0+j 0,0 \\
0,0+j 0,0 \\
0,0+j 0,0\end{array}$ & $\begin{array}{c}0,0+\mathrm{j} 0,0 \\
0,0+\mathrm{j} 0,0 \\
0,07+\mathrm{j} 0,07\end{array}$ \\
\hline $\begin{array}{l}692- \\
675\end{array}$ & $\begin{array}{c}0,07+\mathrm{j} 0,04 \\
0,02+\mathrm{j} 0,0 \\
0,02-\mathrm{j} 0,00\end{array}$ & $\begin{array}{l}0,03+\mathrm{j} 0,00 \\
0,07+\mathrm{j} 0,03 \\
0,032+\mathrm{j} 0,0\end{array}$ & $\begin{array}{c}0,02-\mathrm{j} 0,00 \\
0,03+\mathrm{j} 0,00 \\
0,07+\mathrm{j} 0,04\end{array}$ \\
\hline
\end{tabular}

feeder bus 13 IEEE, untuk menghitung impedansi saluran, menghitung resistansi setiap konduktor. Hitung jarak antar konduktor, menghitung impedansi sendiri setiap fasa, melakukan partisi atau pembagian matriks impedansi. Perhitungan impedansi saluran menggunakan
Tabel 2 Tegangan Awal

Tegangan Kompleks

\begin{tabular}{|c|c|c|c|}
\hline Titik & $\begin{array}{c}\text { PhasaA } \\
\text { (Volt) }\end{array}$ & $\begin{array}{c}\text { Phasa B } \\
\text { (Volt) }\end{array}$ & $\begin{array}{c}\text { Phasa C } \\
\text { (Volt) }\end{array}$ \\
\hline VN0 & $\begin{array}{r}220,0+\mathrm{j} \\
0,0\end{array}$ & $\begin{array}{c}-110,00-\mathrm{j} 190 \\
52\end{array}$ & $\begin{array}{r}-110,00+ \\
j 190,52\end{array}$ \\
\hline VN1 & $\begin{array}{r}220,0+ \\
\text { j0,0 }\end{array}$ & $\begin{array}{c}-110,00-\mathrm{j} 190 \\
52\end{array}$ & $\begin{array}{r}-110,00+ \\
j 190,52\end{array}$ \\
\hline VN2 & $\begin{array}{r}220,0+ \\
\text { j0,0 }\end{array}$ & $\begin{array}{c}-110,00-\mathrm{j} 190 \\
52\end{array}$ & $\begin{array}{r}-110,00+ \\
\mathrm{j} 190,52\end{array}$ \\
\hline VN3 & $\begin{array}{r}220,0+ \\
\text { j0,0 }\end{array}$ & $\begin{array}{c}-110,00-\mathrm{j} 190 \\
52\end{array}$ & $\begin{array}{r}-110,00+ \\
j 190,52\end{array}$ \\
\hline VN4 & $\begin{array}{r}220,0+ \\
\text { j0,0 }\end{array}$ & $\begin{array}{c}-110,00-\mathrm{j} 190 \\
52\end{array}$ & $\begin{array}{r}-110,00+ \\
\mathrm{j} 190,52\end{array}$ \\
\hline VN5 & $\begin{array}{r}220,0+ \\
\text { j0,0 }\end{array}$ & $\begin{array}{c}-110,00-\mathrm{j} 190 \\
52\end{array}$ & $\begin{array}{r}-110,00+ \\
j 190,52\end{array}$ \\
\hline VN6 & $\begin{array}{r}220,0+ \\
\text { j0,0 }\end{array}$ & $\begin{array}{c}-110,00-\mathrm{j} 190 \\
52\end{array}$ & $\begin{array}{r}-110,00+ \\
j 190,52\end{array}$ \\
\hline VN7 & $\begin{array}{r}220,0+ \\
\text { j0,0 }\end{array}$ & $\begin{array}{c}-110,00-\mathrm{j} 190 \\
52\end{array}$ & $\begin{array}{r}-110,00+ \\
\mathrm{j} 190,52\end{array}$ \\
\hline VN8 & $\begin{array}{r}220,0+ \\
\text { j0,0 }\end{array}$ & $\begin{array}{c}-110,00-\mathrm{j} 190 \\
52\end{array}$ & $\begin{array}{r}-110,00+ \\
\mathrm{j} 190,52\end{array}$ \\
\hline VN9 & $\begin{array}{r}220,0+ \\
\text { j0,0 }\end{array}$ & $\begin{array}{c}-110,00-\mathrm{j} 190 \\
52\end{array}$ & $\begin{array}{r}-110,00+ \\
\mathrm{j} 190,52\end{array}$ \\
\hline VN10 & $\begin{array}{r}220,0+ \\
\text { j0,0 }\end{array}$ & $\begin{array}{c}-110,00-\mathrm{j} 190 \\
52\end{array}$ & $\begin{array}{r}-110,00+ \\
\mathrm{j} 190,52\end{array}$ \\
\hline
\end{tabular}

program Julia. Hasil perhitungan impedansi saluran JTR dengan program Julia adalah impedansi konfigurasi, pada saluran JTR, maka hasil impedansi di kalikan dengan panjang saluran dapat dilihat hasil impedansi urutan nol dan urutan positif pada Tabel 1

Berdasarkan Tabel 1 data impedansi yang diperoleh dari hasil komputasi menggunakan program Julia. Dapat dilihat bahwa pengaruh jarak terhadap besarnya nilai impedansi, dari data impedansi yang didapat adalah semakin jauh jarak penghantar maka nilai impedansi akan semakin besar.

\section{G. Perhitungan Tegangan Awal}

Pada perhitungan tegangan awal, data tegangan yang didapata dari feeder 13 IIEE akan dihitung menggunakan program Julia. Dari data tersebut akan dihitung tegangan kompleks awal pada masing-masing bus. Hasil dari perhitungan tegangan awal dengan nilai kompleks dapat dilihat pada Tabel 2 . 
Tabel 3 Tegangan Setiap Titik

Tegangan Kompleks

\begin{tabular}{|c|c|c|c|}
\hline Titik & $\begin{array}{c}\text { PhasaA } \\
\text { (Volt) }\end{array}$ & $\begin{array}{c}\text { PhasaA } \\
\text { (Volt) }\end{array}$ & $\begin{array}{c}\text { PhasaC } \\
\text { (Volt) }\end{array}$ \\
\hline VN0 & $\begin{array}{l}214,53 \\
-j 7.92\end{array}$ & $\begin{array}{c}-109.65- \\
\mathrm{j} 187.62\end{array}$ & $\begin{array}{c}-110.85+ \\
\mathrm{j} 183.17\end{array}$ \\
\hline VN1 & $\begin{array}{c}214,47- \\
j 6,06\end{array}$ & $\begin{array}{c}-109,45- \\
\mathrm{j} 187,88\end{array}$ & $\begin{array}{c}-110,37+ \\
\mathrm{j} 183,33\end{array}$ \\
\hline $\mathrm{VN} 2$ & $\begin{array}{l}214,47 \\
-\mathrm{j} 6,06\end{array}$ & $\begin{array}{c}-108,78- \\
\mathrm{j} 188,62\end{array}$ & $\begin{array}{c}-108,93+ \\
\mathrm{j} 183,83\end{array}$ \\
\hline VN3 & $\begin{array}{l}214,47 \\
-\mathrm{j} 6,06\end{array}$ & $\begin{array}{c}-108,78- \\
\mathrm{j} 188,62\end{array}$ & $\begin{array}{c}-108,93+ \\
\mathrm{j} 183,83\end{array}$ \\
\hline VN4 & $\begin{array}{c}210,89- \\
j 9,85\end{array}$ & $\begin{array}{c}-107,71 \text { - } \\
\mathrm{j} 187,17\end{array}$ & $\begin{array}{l}-108,170 \\
+\mathrm{j} 179,53\end{array}$ \\
\hline VN5 & $\begin{array}{l}210,07 \\
-\mathrm{j} 9,46\end{array}$ & $\begin{array}{c}-107,65- \\
\mathrm{j} 187,35\end{array}$ & $\begin{array}{c}-10,42+j \\
178,82\end{array}$ \\
\hline VN6 & $\begin{array}{l}210,07 \\
-j 9,46\end{array}$ & $\begin{array}{c}-107,65- \\
\mathrm{j} 187,35\end{array}$ & $\begin{array}{c}-10,42+j \\
178,45\end{array}$ \\
\hline VN7 & $\begin{array}{l}209,51 \\
-\mathrm{j} 8,76\end{array}$ & $\begin{array}{c}-107,65- \\
\mathrm{j} 187,35\end{array}$ & $\begin{array}{c}-108,42+ \\
\mathrm{j} 178,82\end{array}$ \\
\hline VN8 & $\begin{array}{l}210,89 \\
-j 9,85\end{array}$ & $\begin{array}{c}-107,71- \\
\mathrm{j} 187,17\end{array}$ & $\begin{array}{c}-108,17+ \\
\mathrm{j} 179,53\end{array}$ \\
\hline VN9 & $\begin{array}{c}210,20 \\
-\mathrm{j} 10,52\end{array}$ & $\begin{array}{c}-107,45- \\
\mathrm{j} 186,92\end{array}$ & $\begin{array}{c}-108,05+ \\
\mathrm{j} 178,72\end{array}$ \\
\hline VN10 & $\begin{array}{c}209,89 \\
-\mathrm{j} 10,34\end{array}$ & $\begin{array}{c}-107,39- \\
\mathrm{j} 186,87\end{array}$ & $\begin{array}{c}-108,12+ \\
\mathrm{j} 178,51\end{array}$ \\
\hline
\end{tabular}

\section{H. Perhitungan Tegangan Kompleks Pada Setiap} Titik

Perhitungan tegangan kompleks pada setiap titik meliputi tegangan dari masing - masing fasa, dengan data yang di pakai adalah impedansi saluran, tegagan awal dan daya pada masing-masing titik, lalu di lakukan perhitungan menggunakan program Julia. Hasil dari perhitungan tegangan kompleks ini disajikan kedalam Tabel 3.

Dari Tabel 3 menyajikan tegangan kompleks pada masing-masing titik, terlihat titik yang memiliki tegangan terkecil yaitu titik ke 10 sebesar 209,89 - j10,34V untuk phasa A, -107,39- j186,8V untuk phasa B, -108,12+ $\mathrm{j} 178,51 \mathrm{~V}$ untuk phasa $\mathrm{C}$ dan titik yang memiliki tegangan paling besar yaitu titik 0 sebesar 214,53 - j6,06V untuk phasa A, -109,65 - j187,62V untuk Phasa B, dan -110,85 $+\mathrm{j} 183,17 \mathrm{~V}$ untuk phasa C.

\section{Perhitungan Arus Pada Masing-Masing Saluran}

Perhitungan arus kompleks akan dilakukan pada masing-masing saluran setelah mendapatkan tegangan kompleks pada masing-masing titik, impedansi saluran, tegagan awal dan daya pada masing-masing titik, lalu di
Tabel 4 Perhitungan Arus Saluran

Arus Kompleks

\begin{tabular}{ccccccc} 
& \multicolumn{2}{c}{ Phasa A } & \multicolumn{2}{c}{ Phasa B } & \multicolumn{2}{c}{ Phasa C } \\
Titik & Mag & Sud & Mag & Sud & Mag & Sud \\
& (A) & ut & (A) & ut & (A) & ut \\
\hline $0-1$ & 29,8 & $-72,6$ & 16,8 & 153,5 & 23,4 & 43,9 \\
$1-2$ & 10,0 & $-71,2$ & 5,0 & 156,3 & 8,0 & 44,4 \\
$0-3$ & 5,6 & $-71,1$ & 3,0 & 155,9 & 4,4 & 45,1 \\
$0-4$ & 0,0 & 0,0 & 0,0 & 0,0 & 0,0 & 0,0 \\
$4-5$ & 19,7 & $-73,3$ & 11,8 & 152,3 & 15,3 & 43,6 \\
$5-6$ & 8,4 & $-71,7$ & 3,8 & 157,3 & 6,8 & 43,8 \\
$5-7$ & 4,3 & $-71,8$ & 1,9 & 157,3 & 3,5 & 43,8 \\
$4-8$ & 4,1 & $-71,6$ & 1,9 & 157,3 & 3,3 & 43,8 \\
$4-9$ & 0,0 & 0,0 & 0,0 & 0,0 & 0,0 & 0,0 \\
$5-10$ & 7,4 & $-77,1$ & 4,1 & 146,8 & 5,7 & 40,4 \\
\hline
\end{tabular}

lakukan perhitungan menggunakan program Julia. Hasil dari perhitungan arus kompleks ini disajikan kedalam Tabel 4.

Dari Tabel 4 menyajikan arus kompleks pada masing-masing saluran. Arus dengan nilai magnitude arus terbesar terjadi pada VN0-1 sebebsar 29,840A untuk phasa $\mathrm{A}, 16,89 \mathrm{~A}$ untuk phasa $\mathrm{B}, 23,45 \mathrm{~A}$ untuk phasa $\mathrm{C}$ dan sudut sebesar $-72,659^{\circ}$ untuk phasa $A, 153,518^{\circ}$ untuk phasa $\mathrm{B}, 43,930^{\circ}$ untuk phasa $\mathrm{C}$.

\section{KESIMPULAN}

Berdasarkan pembahasan dan analisis yang telah dilakukan, adapun kesimpulan yang dapat ditarik adalah sebagai berikut :

1. Dari hasil penelitian bahwa program Julia dapat melakukan perhitungan studi aliran beban tiga fasa pada jaringan tegangan rendah dengan baik.

2. Dari hasil perhitungan didapatkan tegangan pada setiap titik, dengan tegangan pada titik yang memiliki tegangan terkecil yaitu titik ke 10 sebesar 209.89 - j $10.34 \mathrm{~V}$ untuk phasa $\mathrm{A},-107.39-\mathrm{j} 186.87 \mathrm{~V}$ untuk phasa $\mathrm{B},-108.12+\mathrm{j} 178.51 \mathrm{~V}$ untuk phasa $\mathrm{C}$.

3. Pada program ini langsung didapatkan nilai arus pada masing-masing saluran dengan nilai magnitude arus terbesar terjadi pada VN0-1 sebebsar 29.840A untuk phasa A, 16.89A untuk phasa B, 23.45A untuk phasa $\mathrm{C}$. 


\section{REFERENSI}

[1] Shirmohammadi, D. dan S. Cheng, 1994. "A Three-Phase Power Flow Method For Real-Time Distribution System Analysis" dalam IEEE Transaction On Power System (vol.10, No 2, Mei 1995). IEEE.

[2] Bompard, E. dan E. Carpaneto, G. Chicco, dan R. Napoli, 2000. "Convergence Of The Backward/Forward Sweep Method for The LoadFlow Analysis Of Radial Distribution Systems" dalam Electrical Power and Energy System (vol. 22, No 7, 2000).

[3] Ramos De Araujo, L. Débora Rosana Ribeiro Penido, Nélio Alves do Amaral Filho, dan Tatianna Aparecida Pereira Beneteli, 2018. "Sensitivity Analysis Of Convergence Characteristics In Power Flow Methods for Distribution Systems" dalam Electrical Power and Energy System (vol. 97, hal 211-219, 2018).
[4] Teng, J, 2003. "A Direct Approach for Distribution System Load Flow Solutions" dalam IEEE Transaction On Power Delivery (vol. 18, No 3, Juli 2003). IEEE.

[5] Ujjwal Ghatak, V. dan Mukherjee, 2017. "A Fast And Efficient Load Flow Technique for Unbalanced Distribution System" dalam Electrical Power and Energy System (vol. 84, hal 99-110, 2017).

[6] Chang, W, Y. Chu, dan L Wang, 2007. "An Improved Backward/Forward Sweep Load Flow Algorithm for Radial Distribution Systems" dalam IEEE Transaction On Power System (vol. 22, No 2, Mei 2007). IEEE.

[7] Jhonattan Sarmiento, Carreno, M. dan A.C. Zambroni de Souza, 2019. "A Complex-Valued Three-Phase Load Flow for Radial Networks: HighPerformance and Low-Voltage Solution Capability" dalam IEEE Transaction On Power System (vol.34, No 4, Juli 2019). IEEE. 